\title{
Microbiological degradation of phenol using mixed liquors of Pseudomonas putida and activated sludge
}

\author{
Gurusamy Annadurai ${ }^{\mathrm{a}}$, Ruey-Shin Juang ${ }^{\mathrm{b}, *}$, Duu-Jong Lee ${ }^{\mathrm{a}}$ \\ ${ }^{a}$ Department of Chemical Engineering, National Taiwan University, Taipei 106, Taiwan \\ ${ }^{\mathrm{b}}$ Department of Chemical Engineering, Yuan Ze University, Chung-Li 320, Taiwan
}

Accepted 14 January 2002

\begin{abstract}
This work investigated the biodegradation potential of phenol using mixed liquors of Pseudomonas putida (ATCC 31800) and activated sludge. Experiments were made as a function of solution $\mathrm{pH}(6-10)$, temperature $\left(30-36{ }^{\circ} \mathrm{C}\right)$, nitrogen source $\left(\mathrm{NH}_{4}\right)_{2} \mathrm{SO}_{4}$ $(0.5-0.8 \mathrm{~g} / \mathrm{l})$, and carbon source glucose $(0.5-0.8 \mathrm{~g} / \mathrm{l})$. Response surface methodology by the Box-Behnken model was used to examine the role of four process factors on phenol degradation. It was shown that a second-order polynomial regression model could properly interpret the experimental data with an $R^{2}$-value of 0.9997 and an $F$-value of 3605.45 , based on which the maximum degradation of phenol was estimated up to $80.1 \%$ within the range examined. Interactions between process parameters and each significance effect on phenol degradation were also discussed. (C) 2002 Elsevier Science Ltd. All rights reserved.
\end{abstract}

\section{Introduction}

Phenol is a commonly found pollutant in industrial waste effluents, like from the factories of iron-steel, coke petroleum, pesticide, paint solvent, pharmaceutical, wood processing chemicals, and pulp and paper (Aksu and Yener, 1998; Patterson, 1977; Bulbul and Aksu, 1997; Sung et al., 2000). Physicochemical processes (adsorption using activated carbon, for example) and biological processes are often used for removal of phenol and its derivatives from wastewater. The drawbacks of adsorption processes include the needs of adsorbent regeneration, the compensation to adsorbent loss, and the possibility of inducing secondary pollution (Perrich, 1981; Brasquet et al., 1996; Kumar et al., 1987; Singh and Rawas, 1994; Munaf et al., 1993). On the other hand, activated sludge is capable of removing both heavy metals and variety of organic compounds in wastewater stream at a relatively low processing cost (Tsezos and Bell, 1989; Chitra and Chanrakasan, 1996; Vaker et al., 1967; Zumriye et al., 1999; Bux et al., 1999; Ulku et al., 1999).

\footnotetext{
* Corresponding author. Tel.: +886-3-4638-800; fax: + 886-34559-373.

E-mail addresses: cejuang@ce.yzu.edu.tw (R.-S. Juang),djlee@, ccms.ntu.edu.tw (D.-J. Lee).
}

Activated sludge is basically a biomass that contains mainly bacteria and protozoa. The cell wall of the bacteria primarily consists of various organic compounds including chitin, acidic polysaccharides, lipids amino acids and other cellular compounds that could adsorb both the heavy metals and various organics (Takahiro and Eiichi, 1995; Brandt et al., 1999). The protozoa are unicellular, motile, relatively large eucaryotic cells, which could absorb organic compounds and lipids (Aksu and Yener, 1998; Brandt et al., 1997). The use of activated sludge process therefore becomes promising for degrading a variety of organic compounds. Moreover, the $P$. putida had been identified as an effective strain for biodegradation of chlorophenol, resorcinol, and related compounds (Shular and Karge, 1992; Clesseri et al., 1985). In this work, we demonstrated that the use of mixed liquors of $P$. putida and activated sludge could more efficiently degrade phenol compared to the sole application of either of the two biological samples. The effects of various process factors on the phenol degradation were discussed based on response surface methodology.

\section{Response surface methodology}

Response surface methodology is the most widely used statistical technique for bioprocess optimization. 
Response surface experiments identify the response of a system as a function of explanatory variables. It is often used to determine the optimal response for specific range of variable conditions. The interaction among the possible influencing parameters can be evaluated with limited number of experiments.

Response surface methodology is used to determine the optimal response of phenol degradation using $P$. putida and activated sludge as the biomass considering various process parameters like $\mathrm{pH}$, temperature, glucose concentration, and $\left(\mathrm{NH}_{4}\right)_{2} \mathrm{SO}_{4}$ concentration. This optimization process involves three major steps; i.e. performing the statistically designed experiments, estimating the coefficients in a mathematical model, and predicting the response and checking the validity of the model (Box and Behnken, 1959, 1960). For statistical calculations the variable $x_{i}$ was coded $X_{i}$ according to Eq. (1):

$X_{i}=\left(x_{i}-x_{0}\right) / \Delta_{x}, i=1,2,3 \ldots k$

where $X_{i}$ is coded (dimensionless) value of the variable $x_{i}, x_{0}$ is the value of $x_{i}$ at the center point, and $\Delta_{x}$ is the step change.

The system was stated by the following second-order, polynomial equation (Box and Behnken, 1960):

$Y=b_{0}+\sum b_{i} X_{i}+\sum b_{i i} X_{i}^{2}+\sum b_{i j} X_{i} X_{j}$

where $Y$ is the predicted response, $b_{0}$ the offset term, $b_{i}$ the linear effect, $b_{i i}$ the square effect, and $b_{i j}$ the interaction effect. The experimental variables $\mathrm{pH}$, temperature, glucose concentration, and $\left(\mathrm{NH}_{4}\right)_{2} \mathrm{SO}_{4}$ concentration are the critical variables and designated as $X_{1}, X_{2}, X_{3}$, and $X_{4}$, respectively (Table 1). The low, middle, and high levels of each variable (equally spaced) are designated $-1,0$, and +1 respectively.

The mathematical relationship of the response $Y$ and these four variables can be approximated by the quadratic (second-degree) polynomial equation:

$$
\begin{aligned}
Y & =b_{0}+b_{1} X_{1}+b_{2} X_{2}+b_{3} X_{3}+b_{4} X_{4}+b_{11} X_{1}^{2}+b_{22} X_{2}^{2} \\
& +b_{33} X_{3}^{2}+b_{44} X_{4}^{2}+b_{12} X_{1} X_{2}+b_{13} X_{1} X_{3} \\
& +b_{14} X_{1} X_{4}+b_{23} X_{2} X_{3}+b_{24} X_{2} X_{4}+b_{34} X_{3} X_{4}
\end{aligned}
$$

This design is preferred because relatively few combinations of the variables are adequate to estimate potentially complex response function. The total 29 experiments are needed to calculate 15 coefficients of the second-order polynomial regression model. This model contains one block term, four linear terms, four quadratic terms, and six interaction terms, which is applied by using design of experiments for phenol degradation.
Table 1

The levels of variables chosen for the trials

\begin{tabular}{llll}
\hline $\mathrm{pH}$, & Temperature & $\begin{array}{l}\text { Glucose } \\
\text { concentration } \\
(\mathrm{g} / \mathrm{l}), X_{3}\end{array}$ & $\begin{array}{l}\left(\mathrm{NH}_{4}\right)_{2} \mathrm{SO}_{4} \\
\text { concentration } \\
(\mathrm{g} / \mathrm{l}), X_{4}\end{array}$ \\
\hline $7.0(-1)$ & $30(-1)$ & $0.5(-1)$ & $0.5(-1)$ \\
$8.0(0)$ & $32(0)$ & $0.6(0)$ & $0.6(0)$ \\
$9.0(+1)$ & $34(+1)$ & $0.7(+1)$ & $0.7(+1)$
\end{tabular}

\section{Experimental}

\subsection{Materials}

Phenol (99\% purity), 4-amino antipyrine, and other chemicals were offered from Merck. Co. The microorganism P. putida (ATCC 31800) was purchased from Food Industry Research \& Development Institute, Hsinchu, Taiwan. Samples of activated sludge were obtained from President Enterprises Co., Chungli, Taiwan. The microorganism was stored at $4{ }^{\circ} \mathrm{C}$ in a medium containing beef extract $1.0 \mathrm{~g} / 1$, yeast extract $2.0 \mathrm{~g} / 1$, peptone $5.0 \mathrm{~g} / 1, \mathrm{NaCl} 1.0 \mathrm{~g} / \mathrm{l}$, and agar $20 \mathrm{~g} / 1$. The $\mathrm{pH}$ of the original activated sludge was 6.25 , which was adjusted to 7.0 by adding $1 \mathrm{~mol} / 1 \mathrm{NaOH}$.

\subsection{Experimental procedures}

The experimental range was optimized to maximize phenol degradation with the Box-Behnken design method considering the solution $\mathrm{pH}$ of $6,7,8,9,10$; temperature of $30,32,34,36^{\circ} \mathrm{C}$; glucose concentration of $0.5,0.6,0.7,0.8 \mathrm{~g} / 1$; and $\left(\mathrm{NH}_{4}\right)_{2} \mathrm{SO}_{4}$ concentration of $0.5,0.6,0.7,0.8 \mathrm{~g} / 1$. Experiments were carried out in conical flasks containing mineral medium in a shaker at $120 \mathrm{rpm}$ for $48 \mathrm{~h}$, in which pure activated sludge $\left(1.6<10^{5} \mathrm{CFU} / \mathrm{ml}\right)$ and pure $P$. putida $\left(1.6 \times 0^{5} \mathrm{CFU} /\right.$ $\mathrm{ml})$ were inoculated. Two mixed liquors of activated sludge and $P$. putida, $1.6 \times 10^{5} / 1.6 \times 10^{5} \mathrm{CFU} / \mathrm{ml}(\mathrm{A})$ and $8 \times 10^{4} / 8 \times 10^{4} \mathrm{CFU} / \mathrm{ml}$ (B), were also inoculated. The $\mathrm{CFU}$ is determined by the agar plat count method (Standard Methods for microbiological examination). The concentration of phenol undegraded in the solution was determined by a Hitachi UV-vis spectrophotometer (Model U2000) using 4-amino antipyrine as a color reagent $\left(\lambda_{\max }=500 \mathrm{~nm}\right)($ Clessceri et al., 1985).

\section{Results and discussion}

\subsection{Phenol degradation}

The degradation of phenol with pure $P$. putida, pure activated sludge, and the mixed liquors at different initial phenol concentrations is shown in Fig. 1. It is 


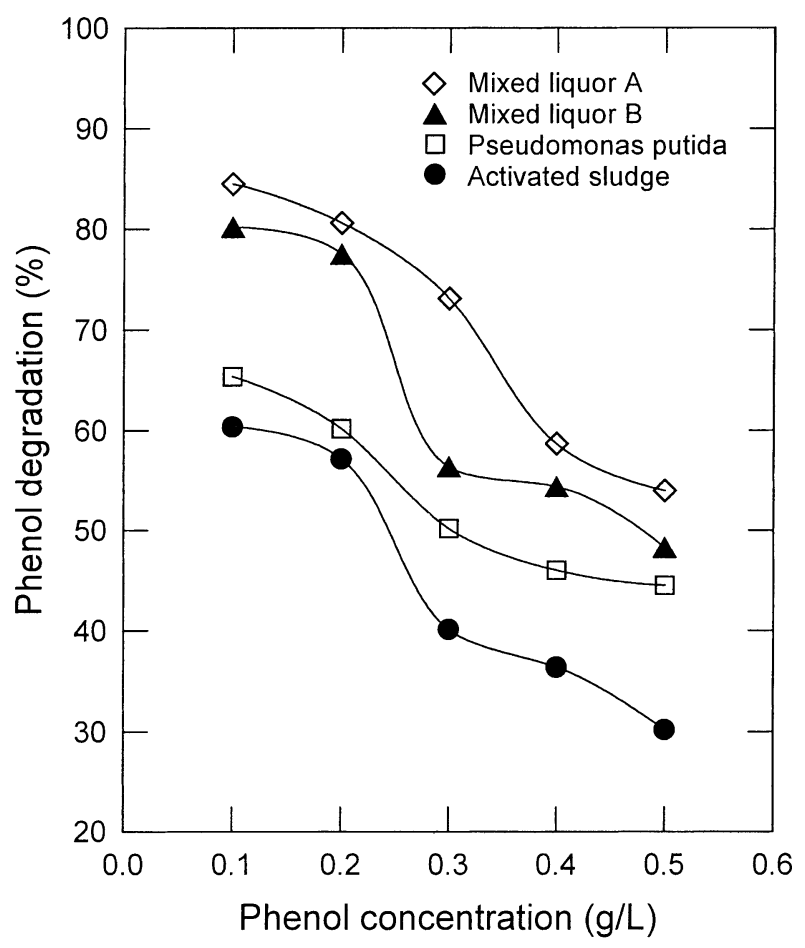

Fig. 1. Effect of initial concentration of phenol on phenol degradation in minimal medium. Conditions: $\mathrm{pH} 7.0,30^{\circ} \mathrm{C}, 0.5 \mathrm{~g} / 1$ glucose, and 0.5 $\mathrm{g} / \mathrm{l}\left(\mathrm{NH}_{4}\right)_{2} \mathrm{SO}_{4}$.

found that the degradation declines with increasing the initial phenol concentration although the total amount of degradation still increases. The degradation percentage follows activated sludge $<P$. putida $<$ mixed liquor $\mathrm{B}<$ mixed liquor A. Restated, the $P$. putida does exhibit a better performance on phenol degradation compared to pure activated sludge test, as also reported earlier (Chitra and Chanrakasan, 1996). The superiority of using mixed liquors to degrade phenol is clearly demonstrated. A synergistic effect of the mixed liquors on phenol degradation is observed when the cases of pure microorganisms and the mixed liquor B are compared. At an initial phenol concentration of $0.5 \mathrm{~g} / 1,22 \%$ of phenol is degraded using pure activated sludge for 48 $\mathrm{h}$. It is interesting to note that there is a distinct color change to brownish black, which may be due to the toxic effect of phenol on the sludge.

The effects of $\mathrm{pH}$, temperature, glucose concentration (carbon source), and $\left(\mathrm{NH}_{4}\right)_{2} \mathrm{SO}_{4}$ concentration (nitrogen source) on phenol degradation are shown in Figs. 2-4. It is evident from Fig. 2 that phenol degradation is deteriorated as the medium $\mathrm{pH}$ deviates from neutral condition. The $\mathrm{pH}$ surge significantly affects the biochemical reactions required for phenol degradation. Tests with pure $P$. putida could not efficiently resist $\mathrm{pH}$ change. On the other hand, the presence of activated sludge could markedly compensate the addition of acid or alkaline.

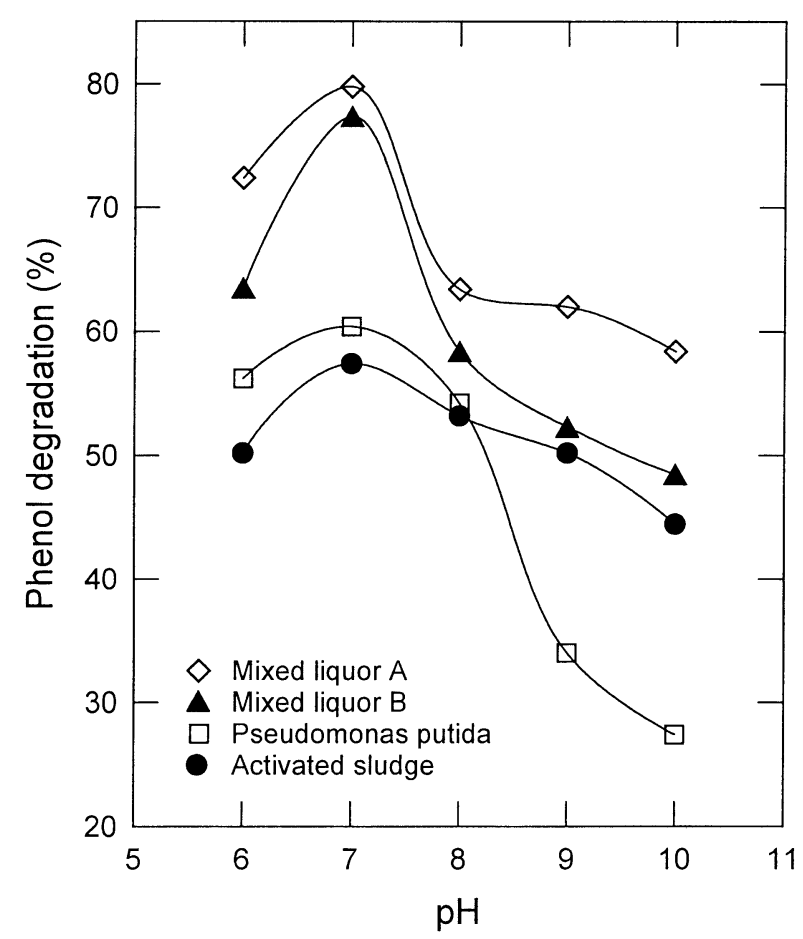

Fig. 2. Effect of $\mathrm{pH}$ on phenol degradation in minimal medium. Conditions: $30{ }^{\circ} \mathrm{C}, 0.2 \mathrm{~g} / 1$ phenol, $0.5 \mathrm{~g} / 1$ glucose, and $0.5 \mathrm{~g} / \mathrm{l}$ $\left(\mathrm{NH}_{4}\right)_{2} \mathrm{SO}_{4}$.

As shown in Fig. 3, phenol is more readily to be biodegraded at a lower concentration of glucose or $\left(\mathrm{NH}_{4}\right)_{2} \mathrm{SO}_{4}$. The enhancement of phenol degradation with increasing glucose concentration could be realized as a process during which the hardly degraded compounds (phenol) could be degraded together with the more readily degraded glucose. Under the ranges studied, the degradation decreases when temperature increases (Fig. 4).

An increase in the cell mass would improve the biodegradation of phenol. Addition of glucose to the medium is useful to increase the volumetric degradation of $P$. putida cultures to high cell concentration. The high cell density by the $P$. putida cells was stimulated with an increase in glucose concentration up to $0.5-0.6 \mathrm{~g} / \mathrm{l}$. In addition to the mineral medium, $0.5-0.6 \mathrm{~g} / 1$ of glucose is found to the best for phenol degradation, although an increase in biomass is achieved with increasing glucose concentration.

Inoculated activated sludge may find application potentials in removal of phenol from waste streams. It may have more advantages than pure single or mixed cell cultures in view of its large consortium of microbes, which are stabilized by natural exopolysaccharides since they can also sorb organic and inorganic matter such as heavy metals. Factors affecting of the bacteria inoculated into activated sludge generally include the perdition by protozoa, competition with indigenous bacterial populations, the presence of growth inhibitors, concentration of 


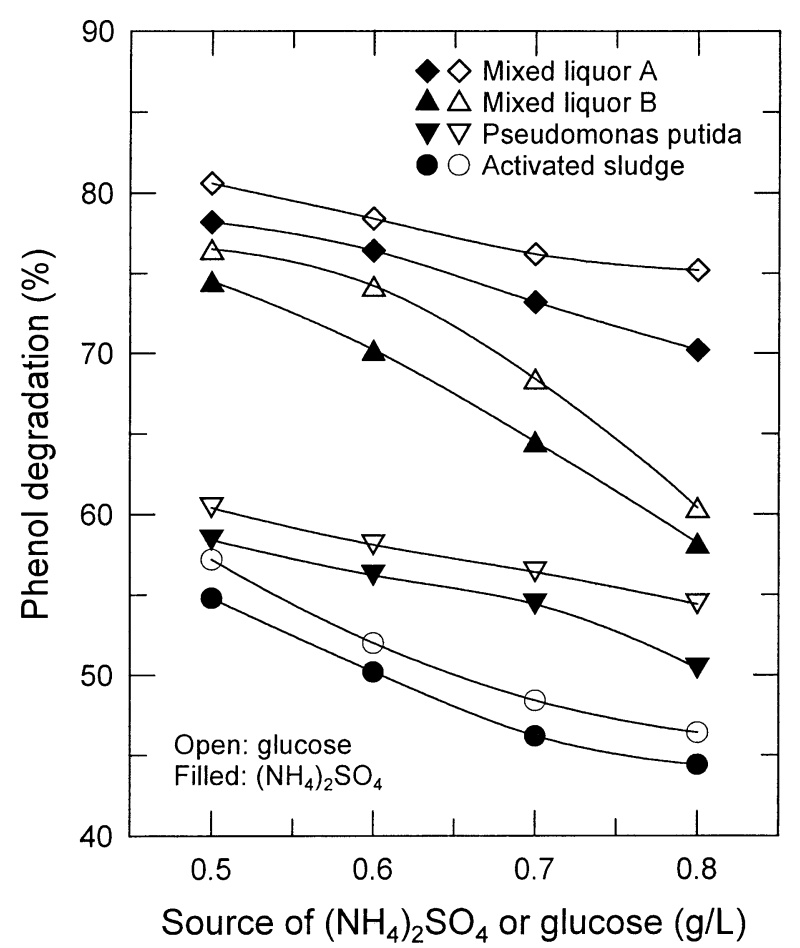

Fig. 3. Effect of concentrations of glucose and $\left(\mathrm{NH}_{4}\right)_{2} \mathrm{SO}_{4}$ on phenol degradation in minimal medium. Conditions: $\mathrm{pH} 7.0,30^{\circ} \mathrm{C}, 0.2 \mathrm{~g} / \mathrm{l}$ phenol.

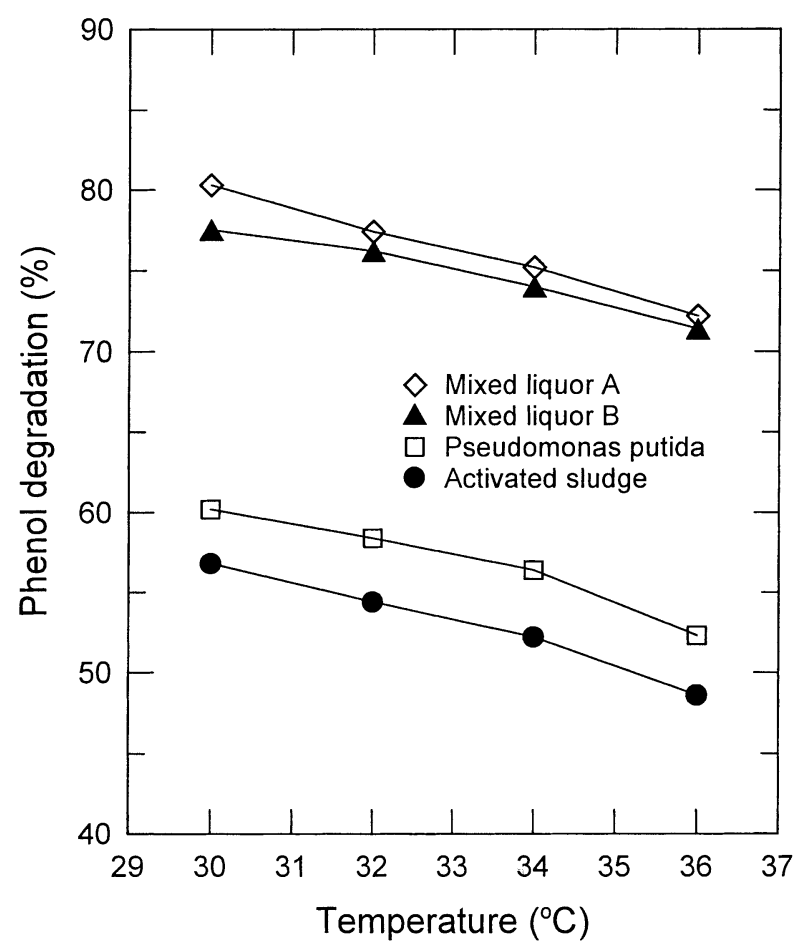

Fig. 4. Effect of temperature on phenol degradation in minimal medium. Conditions: pH 7.0, $0.2 \mathrm{~g} / 1$ phenol, $0.5 \mathrm{~g} / 1$ glucose, and $0.5 \mathrm{~g} / 1$ $\left(\mathrm{NH}_{4}\right)_{2} \mathrm{SO}_{4}$. nutrients, and physical factors. Activated sludge mainly predates suspended cells and the cells in pure culture of strain P. putida keep suspended conditions. It is therefore assumed that the perdition by protozoa in activated sludge will mainly cause the decrease of strain $P$. putida cells at the initial period of inoculation. Some of the inoculated cells are supported to have survived by adhering themselves to the sludge floc and grow on the floc to exhibit degradation activity.

\subsection{Regressing model}

The application of response surface methodology offers, on the basis of parameter estimate, an empirical relationship between the response variable and the test variable and the test variables are related by the following quadratic expression. With the dependence demonstrated in Figs. 2-4, the optimal parameter set could be estimated using the Box-Behnken method. A regression model containing four linear $\left(X_{i}\right)$, four quadratic $\left(X_{i}^{2}\right)$, and six cross-interactions $\left(X_{i} X_{j}\right)$ terms plus 1 block term is used. The results from regressing model in the case of pure $P$. putida test, pure activated sludge test, and mixed liquor $\mathrm{A}$ and $\mathrm{B}$ tests are represented by Eqs. (4)-(7), respectively.

$$
\begin{aligned}
Y & =35.2+0.23 X_{1}+0.67 X_{2}-0.31 X_{3}-0.17 X_{4} \\
& -1.37 X_{1}^{2}-1.25 X_{2}^{2}-1.75 X_{3}^{2}-0.48 X_{4}^{2} \\
& +0.36 X_{1} X_{2}-0.31 X_{1} X_{3}+0.15 X_{1} X_{4} \\
& +0.58 X_{2} X_{3}-0.92 X_{2} X_{4}+0.31 X_{3} X_{4} \\
Y & =52.4-0.82 X_{1}-1.62 X_{2}-1.46 X_{3}-2.00 X_{4} \\
& -6.41 X_{1}^{2}+2.07 X_{2}^{2}+1.23 X_{3}^{2}+0.35 X_{4}^{2} \\
& +0.87 X_{1} X_{2}+0.15 X_{1} X_{3}+0.70 X_{1} X_{4} \\
& +0.072 X_{2} X_{3}+0.35 X_{2} X_{4}+0.70 X_{3} X_{4} \\
Y & =76.4-1.06 X_{1}-1.41 X_{2}-2.19 X_{3}-2.25 X_{4} \\
& -16.21 X_{1}^{2}-0.099 X_{2}^{2}-0.34 X_{3}^{2}-2.17 X_{4}^{2} \\
& +0.016 X_{1} X_{2}+0.23 X_{1} X_{3}+0.55 X_{1} X_{4} \\
& +1.00 X_{2} X_{3}+0.55 X_{2} X_{4}-0.64 X_{3} X_{4} \\
Y & =54.30-1.08 X_{1}-2.17 X_{2}-1.79 X_{3}-1.61 X_{4} \\
& -5.71 X_{1}^{2}+2.69 X_{2}^{2}+3.83 X_{3}^{2}+0.70 X_{4}^{2} \\
& +0.050 X_{1} X_{2}-2.20 X_{1} X_{3}+2.00 X_{1} X_{4} \\
& +1.62 X_{2} X_{3}+0.23 X_{2} X_{4}+0.40 X_{3} X_{4}
\end{aligned}
$$

Notably, the maximum phenol degradation could reach $58.8 \%$ with pure $P$. putida as the microorganism, 
$35.2 \%$ with pure activated sludge, and up to $80.1 \%$ with the mixed liquors. The analysis of variance (ANOVA) for experimental results gives that the $F$-values in these three systems are rather high (>519.6), indicating the feasibility of the use of the regressing models to correlate the experimental data. In the case of the mixed liquor A (Table 2), e.g. an $F$-value of 3605.45 and an $R^{2}$-value of 0.9997 are obtained. The lack of fit is significant because the probability value $(\operatorname{Prob}>F)$ is below 0.0001 . A small probability indicates that adding the quadratic terms has improved the regression model (Box and Behnken, 1959, 1960). Moreover, the standard deviation between the measured and modeled results [Eq. (6)] is only $0.29 \%$ (Root MSE/Dep Mean).

For each parameter and parameter combination, the $t$-statistic value and the individual significance probability (Prob) of $t$-value greater than $t$ are shown in Table 3. Individual parameters and their combinations that meet $5 \%$ or less significance probability criteria are

Table 2

Regression analysis and response surface model fitting (ANOVA) for degradation of phenol using the mixed liquor A of Pseudomonas putida and activated sludge

\begin{tabular}{lrrrrr}
\hline Source & $\begin{array}{l}\text { Sum of } \\
\text { squares }\end{array}$ & $\begin{array}{l}\text { Degree of } \\
\text { freedom }\end{array}$ & $\begin{array}{l}\text { Mean } \\
\text { squares }\end{array}$ & $F$-value & Prob $>F$ \\
\hline Model & 1962.96 & 14 & 140.21 & 3605.45 & $<0.0001$ \\
Residual & 0.54 & 14 & 0.039 & & \\
Lack of fit & 0.54 & 10 & 0.054 & $6.366 \mathrm{E}+07$ & $<0.0001$ \\
Pure error & 0.00 & 4 & 0.000 & & \\
Total & 1963.50 & 28 & & & \\
Root MSE & 0.20 & & & & \\
Dep Mean $^{\mathrm{b}}$ & 68.61 & & & & \\
& $R^{2}=0.9997$ & & & & \\
\hline
\end{tabular}

a Root MSE $=$ square root of the mean square error.

b Dep Mean $=$ dependent mean (overall mean of the response).

Table 3

Coefficients of the model [Eq. (6)] for phenol degradation using the mixed liquor A of Pseudomonas putida and activated sludge

\begin{tabular}{lclrc}
\hline Coefficient & Value & $\begin{array}{l}\text { Standard } \\
\text { error }\end{array}$ & $\begin{array}{c}t \text { for } \mathrm{H}_{0}: \\
\text { coeff. }=0\end{array}$ & Prob $>|t|$ \\
\hline$b_{0}$ & 76.40 & 0.088 & & \\
$b_{1}$ & -1.06 & 0.057 & -18.61 & $<0.0001^{*}$ \\
$b_{2}$ & -1.41 & 0.057 & -24.81 & $<0.0001^{*}$ \\
$b_{3}$ & -2.19 & 0.057 & -38.47 & $<0.0001^{*}$ \\
$b_{4}$ & -2.25 & 0.057 & -39.58 & $<0.0001^{*}$ \\
$b_{11}$ & -16.21 & 0.077 & -209.34 & $<0.0001^{*}$ \\
$b_{22}$ & -0.099 & 0.077 & -1.28 & $0.2211^{*}$ \\
$b_{33}$ & -0.34 & 0.077 & -4.36 & $0.0006^{*}$ \\
$b_{44}$ & -2.17 & 0.077 & -28.06 & $<0.0001^{*}$ \\
$b_{12}$ & 0.16 & 0.099 & 1.60 & 0.1325 \\
$b_{13}$ & 0.23 & 0.099 & 2.28 & $0.0387^{*}$ \\
$b_{14}$ & 0.55 & 0.099 & 5.63 & $<0.0001^{*}$ \\
$b_{23}$ & 1.00 & 0.099 & 10.14 & $<0.0001^{*}$ \\
$b_{24}$ & 0.55 & 0.099 & 5.58 & $<0.0001^{*}$ \\
$b_{34}$ & -0.64 & 0.099 & -6.44 & $<0.0001^{*}$ \\
\hline
\end{tabular}

* Significant parameter. marked with an asterisk. It is evident that the values of the coefficients $b_{22}$ and $b_{12}$ in model equation, both of which relate to $X_{2}$, are comparatively small. This means that the temperature, at least under the ranges studied, is insignificant and the other three factors play an important role.

\subsection{Maximum phenol degradation}

The data presented in Figs. 2-4 can be summarized into Figs. 5-8. As shown in Fig. 5, the maximum degradation $(80.1 \%)$ occurs at $\mathrm{pH}$ range $6.8-7.2$ and temperature range $30-30.6{ }^{\circ} \mathrm{C}$. We fix the level of $\mathrm{pH}$ at 7.0 and temperature at $30^{\circ} \mathrm{C}$ in subsequent discussion. Degradation of phenol remains almost constant during a large portion of the starting period when the $\mathrm{pH}$ is about 7-8. The experimental system is $\mathrm{pH}$ varying, which ranges from 7 to 9 . The good performance may be due to the fact that the adaptation of the most of organisms cannot tolerate $\mathrm{pH}$ levels below 4.0 or above 9.0 (Kim and Armstrong, 1981). The permeated substances can upset the internal $\mathrm{pH}$ balance since the bacterial activity decreases as the $\mathrm{pH}$ deviates from neutral conditions.

In general, conventional biological treatment processes can operate at low temperature if sufficient time is allowed. However, microbiological degradation of phenol in industrial waste effluents is affected by temperature in an unexpected manner (Novak, 1974; Vela and Rainey, 1976; Vela and James, 1978; Inniss, 1975). The limit of optimal temperature range is determined by other environment factors such as the $\mathrm{pH}$, temperature,

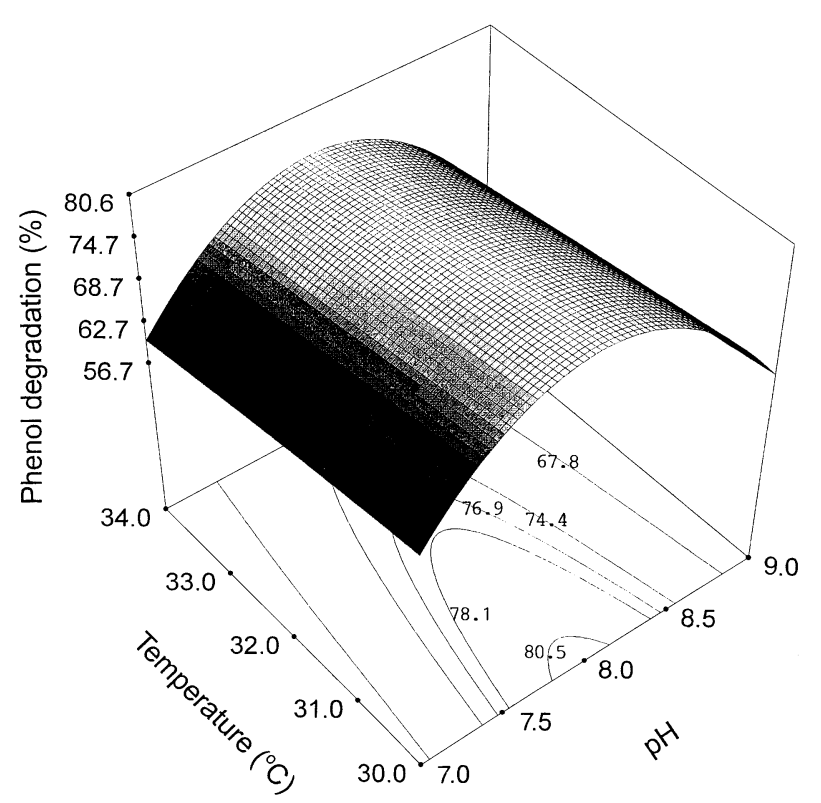

Fig. 5. Response surface optimization of phenol degradation vs. $\mathrm{pH}$ and temperature using the mixed liquor A of Pseudomonas putida and activated sludge. 


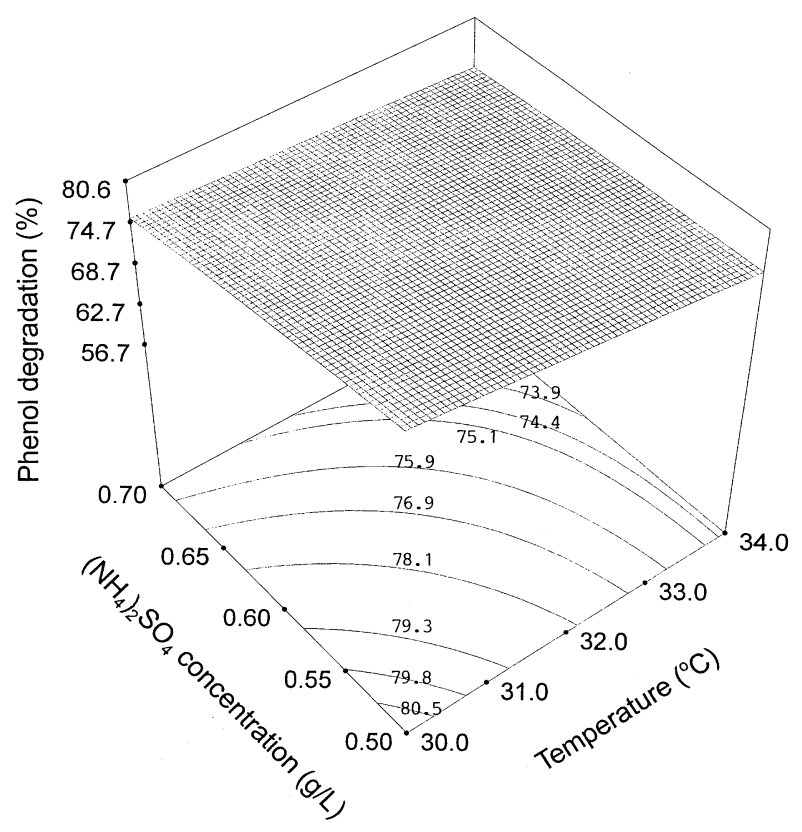

Fig. 6. Response surface optimization of phenol degradation vs. temperature and $\left(\mathrm{NH}_{4}\right)_{2} \mathrm{SO}_{4}$ concentration using the mixed liquor $\mathrm{A}$ of Pseudomonas putida and activated sludge.

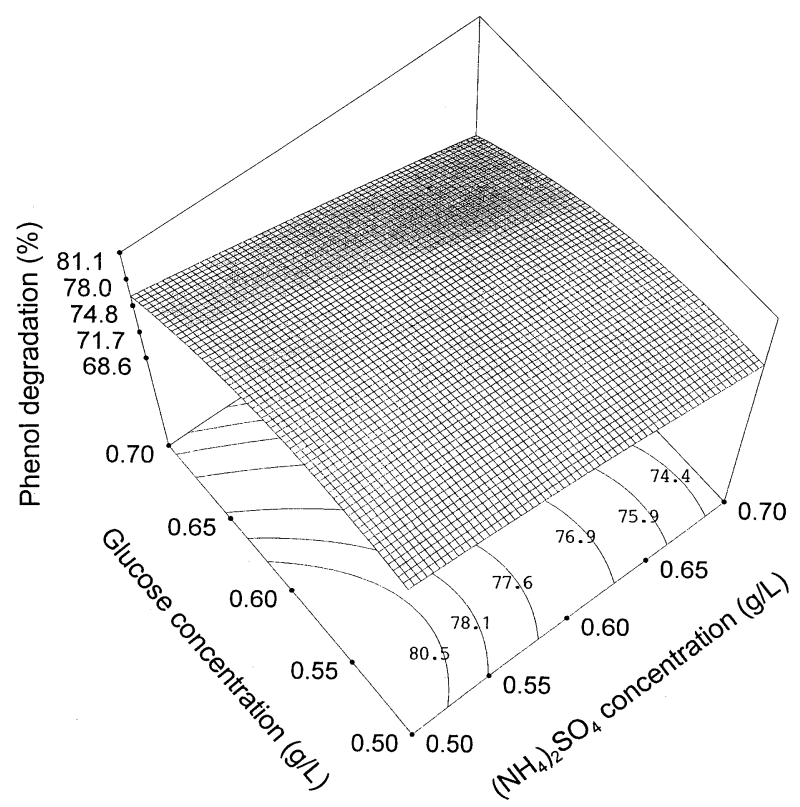

Fig. 7. Response surface optimization of phenol degradation vs. concentrations of glucose and $\left(\mathrm{NH}_{4}\right)_{2} \mathrm{SO}_{4}$ using the mixed liquor $\mathrm{A}$ of Pseudomonas putida and activated sludge.

carbon and nitrogen sources. Here, the maximum degradation of phenol with the mixed liquors is $80.1 \%$ (Fig. 6) under the conditions of $0.2 \mathrm{~g} / 1$ phenol, temperature $30-30.6{ }^{\circ} \mathrm{C}$, and $\left(\mathrm{NH}_{4}\right)_{2} \mathrm{SO}_{4}$ concentration 0.5 to $0.55 \mathrm{~g} / 1$.

The maximum degradation (80.1\%) occurs at $0.5-0.6$ $\mathrm{g} / \mathrm{l}$ of $\left(\mathrm{NH}_{4}\right)_{2} \mathrm{SO}_{4}$ and glucose (Fig. 7). Fig. 8 shows that the maximum degradation $(80.1 \%)$ occurs at glucose of

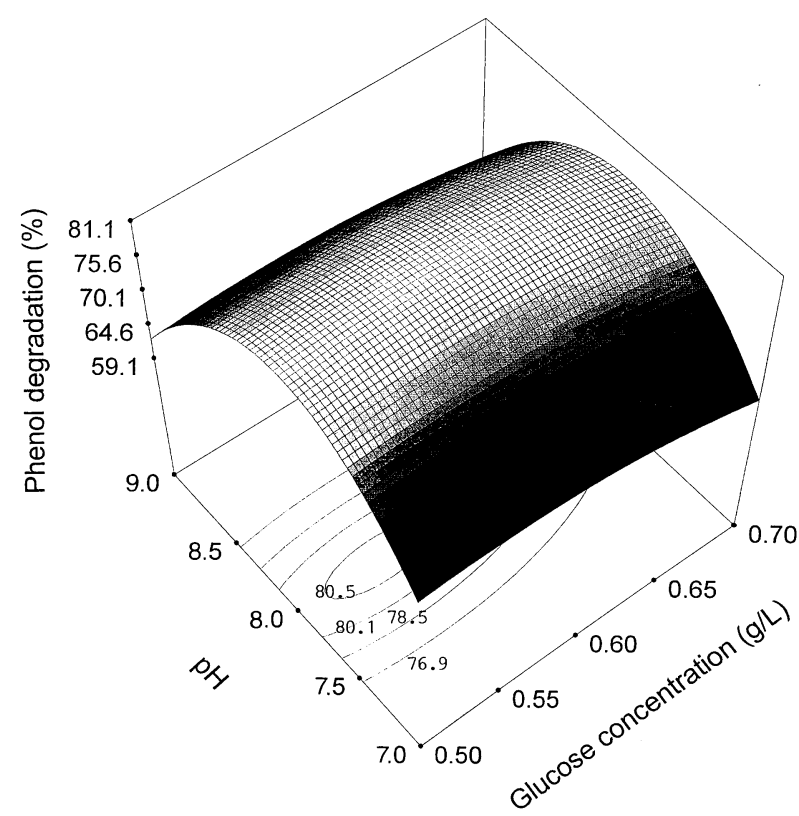

Fig. 8. Response surface optimization of phenol degradation vs. glucose concentration and $\mathrm{pH}$ using the mixed liquor A of Pseudomonas putida and activated sludge.

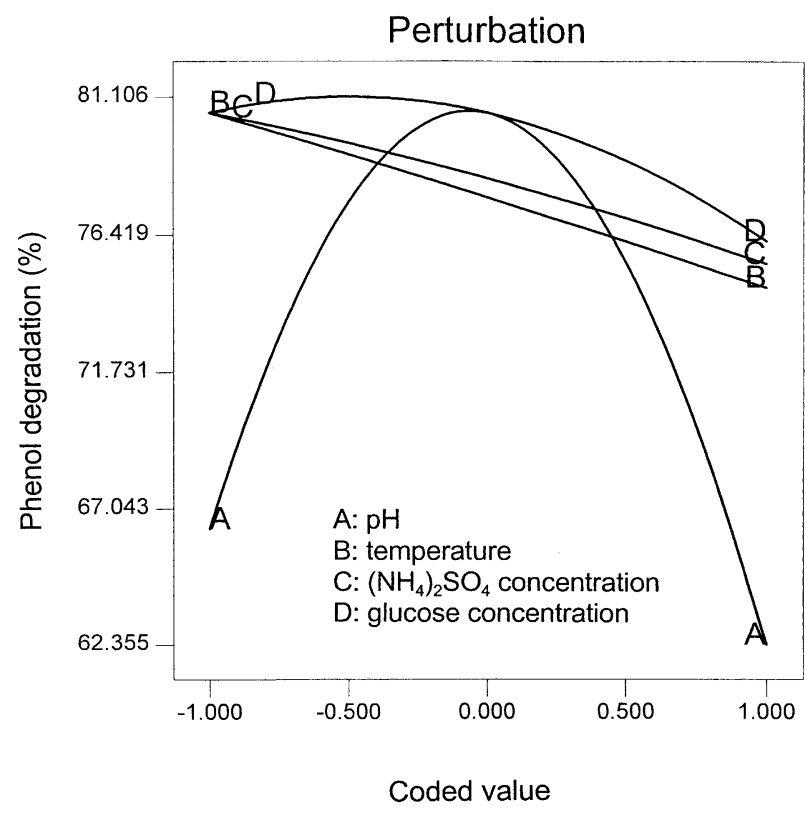

Fig. 9. Factorial plot representing the individual variables effect on phenol degradation using the mixed liquor A of Pseudomonas putida and activated sludge.

0.5-0.6 g/1 and $\mathrm{pH}$ of 6.8-7.1. Kim and Armstrong, (1981) have noted that at low glucose concentrations the cells (activated sludge) tend to degrade phenol more readily. On the other hand, Soda and Uadke (1980) demonstrated that $T$. cutaneum would more efficiently utilize phenol with the presence of glucose. Our results can apparently correlate with the results of Kim and Armstrong (1981). 


\subsection{Trace plot}

From the trace plot, Fig. 9, each of nutrients used in this study has its individual effect on phenol degradation by mixed liquors of $P$. putida and activated sludge. The gradual increase in degradation to maximum is seen with increasing $\mathrm{pH}$ from 7 (coded value $=-1)$ to 8 (coded value $=0)$; temperature 30 $($ coded value $=-1)$ to $32{ }^{\circ} \mathrm{C}($ coded value $=0)$; glucose $0.5($ coded value $=-1)$ to $0.6 \mathrm{~g} / 1($ coded value $=0)$, and $\left(\mathrm{NH}_{4}\right)_{2} \mathrm{SO}_{4} 0.5$ (coded value $\left.=-1\right)$ to $0.6 \mathrm{~g} / 1$ (coded value $=0$ ). In a word, the optimal level exists at $\mathrm{pH} 7$ (coded value $=-1)$, temperature $30{ }^{\circ} \mathrm{C} \quad($ coded value $=-1)$, glucose $0.5 \mathrm{~g} / 1$ (coded value $=-1)$ and $\left(\mathrm{NH}_{4}\right)_{2} \mathrm{SO}_{4} 0.5 \mathrm{~g} / 1$ (coded value $\left.=-1\right)$.

\section{Conclusions}

The biodegradation of phenol in aqueous solutions using P. putida (ATCC 31800), activated sludge, or both was investigated. Phenol degradation was deteriorated as the medium $\mathrm{pH}$ deviated from neutral condition, and became less efficient with increasing temperature, the concentrations of carbon (glucose) and nitrogen $\left(\left(\mathrm{NH}_{4}\right)_{2} \mathrm{SO}_{4}\right)$ sources. It was also shown that the mixed liquors had a best ability for phenol degradation than pure activated sludge and $P$. putida. Optimization of four process parameters $(\mathrm{pH}$, temperature, carbon and nitrogen sources) by using the Box-Behnken method, for example with the mixed liquor A, showed a good fit with an $R^{2}$-value of 0.9997 and an $F$-value of 3605.45 . Also, the second-degree regression model well fitted the experimental data with a standard deviation of $0.29 \%$. All the three variables except temperature were significant on phenol degradation under the ranges studied. Optimization of $\mathrm{pH}(7.0)$, temperature $\left(30{ }^{\circ} \mathrm{C}\right)$, glucose concentration $(0.5 \mathrm{~g} / \mathrm{l})$, and $\left(\mathrm{NH}_{4}\right)_{2} \mathrm{SO}_{4}$ concentration $(0.5 \mathrm{~g} / \mathrm{l})$ gave a maximum phenol degradation of $80.5 \%$ by the mixed liquor A. Experimental design analysis could allow selecting optimal conditions in such biodegradation processes.

\section{Acknowledgements}

Support for this work by the National Science Council, ROC, under Grant NSC89-2211-E-002-008 is highly appreciated. The authors wish to express our sincere thanks to Mr. Mark Anderson, DOE, Instructor and Stat Ease Corporation principal for allowing us to use his experiment design program [version 5.0.7.1999].

\section{References}

Aksu, S., Yener, J., 1998. Investigation of biosorption of phenol and monochlorinated phenols on the dried activated sludge. Process Biochem. 33, 649-655

Box, G.E.P., Behnken, D.W., 1959. A basic for the selection of a response surface design. J. Am. Stat. Soc. 54, 622-654.

Box, G.E.P., Behnken, D.W., 1960. Some new three-level design for the study of quantitative variables. Technometrics 2, 455-475.

Brandt, C., Zeng, A., Deckwer, W., 1997. Adsorption and desorption of pentachlorophenol on cells of $M$. chlorophenolicum Pep-I. Biotechnol. Bioeng 55, 480-489.

Brasquet, C., Rouss, J., Subrenat, E., Le Cloriec, P., 1996. Adsorption and selectivity of activated carbon fibers application to organics. Environ. Technol. 17, 1245-1252.

Bulbul, G., Aksu, Z., 1997. Investigation of wastewater treatment containing phenol using free and $\mathrm{Ca}$-alginated gel immobilized Pseudomonas putida in a batch stirred reactor. Turkish J. Eng. Environ. Sci. 21, 175-181.

Bux, F., Akkinson, B., Kasan, K., 1999. Zinc biosorption by waste activated and digested sludges. Water Sci. Technol. 39 (10-11), 127130 .

Chitra, S., Chanrakasan, G., 1996. Response of phenol degrading Pseudomonas pictorium to changing loads of phenolic compounds. J. Environ. Sci. Health A31, 599-619.

Clessceri, C.S., Greenberg, A.B., Trussel, R.R., 1985. Standard methods for the determination of water and wastewater. APHA, Washington, DC 5.48-5.53.

Inniss, W.E., 1975. Interaction of temperature on organophilic microorganisms. Ann. Rev. Microbiol 29, 445-465.

Kim, J.W., Armstrong, M.E., 1981. A comprehensive study on the biological treatabilities of phenol and methanol. II. The effect of temperature, $\mathrm{pH}$ salinity and nutrients. Water Res. 15, 12331247.

Kumar, S., Upadhyay, S.N., Upadhya, Y.D., 1987. Removal of phenols by adsorption of fly ash. J. Chem. Technol. Biotechnol 37, 281292.

Munaf, E., Zkin, R., Kurniad, R., Kurniadi, I., 1993. The use of rice husk for removal of phenol from waste water as studied using 4aminoantipyrine spectrophotometric method. Environ. Technol 18, 355-358.

Novak, J.T., 1974. Temperature-substrate interactions in biological treatment. J. Water Pollut. Cont. Fed 46, 1984-1986.

Patterson, J.N., 1997. Waste Water Treatment Technology. Ann Arbor Science, New York.

Perrich, J.R., 1981. Activated Carbon. Adsorption for Wastewater Treatment. CRC Press, Boca Raton, Florida.

Shular, M.C., Karge, F., 1992. Bioprocess Engineering. Basic Concepts, Prentice Hall, New Jersey.

Singh, B.K., Rawas, N.S., 1994. Comparative sorption equilibrium studies of toxic phenols on fly ash and impregnated fly ash. J. Chem. Technol. Biotechnol. 61, 307-317.

Soda, M., Udake, L., 1980. Preferential utilization of phenol and glucose by Trichosporon cutaneum possessing a partially substituted catechol 1,2-oxygenase. App. Environ. Microbiol 39, 1129-1133.

Sung, R.H., Soydoa, V., Hiroaki, O., 2000. Biodegradation by mixed microorganism of granular activated carbon loaded with a mixture of phenols. Biotechnol. Letters 22, 1093-1096.

Takahiro, K., Eiichi, M., 1995. Survial of a non-flocculating bacterium Thiobacillus thioparus TK-1 inoculated to activated sludge. Water Res. 29, 2751-2754.

Tsezos, M., Bell, J.P., 1989. Comparison of biosorption and desorption of hazardous organic pollutants by live and dead biomass. Water Res. 23, 563-568

Ulku, Y., Goksel, N.D., Celal, F.G., 1999. Effect of chromium(VI) on the biomass yield of activated sludge. Enzyme Microbiol. Technol. $25,48-54$. 
Vaker, D., Connell, C.H., Wells, W.W., 1967. Phosphate removal through municipality waste water treatment at San Antonjo Texas. J. Water Pull. Cont. Fed. 39, 750-771.

Vela, G.R., Rainey, J.G., 1976. Microbiological degradation of phenol in the effluent from a water treatment. Text. J. Sci. 27, 197-206.
Vela, G.R., James, R.R., 1978. The effect of temperature on phenol degradation in waste water. Can. J. Microbiol. 24, 1366-1370.

Zumriye, A., Derya, A., Elif, R., Burcin, K., 1999. Simultaneous biosorption of phenol and nickel from binary mixtures onto dried aerobic activated sludge. Process Biochem. 35, 301-308. 